\title{
Effective Treatment for Addicted Criminal Justice Clients
}

\author{
Harvey Weiner, DSW \\ Arlin Silberman, DO \\ Peter Glowacki, MD \\ W. Charles Folks, MSW
}

\begin{abstract}
Addicted criminal justice clients present unique challenges because of the complex biopsychosocial problems which frequently accompany their addiction. An overview of the current understanding of addictive disease is presented, including the important distinction between abstinence and sobriety.
\end{abstract}

In the Eagleville Recovery Program, each client's medical, psychosocial, educational, vocational and psychiatric assessments are used to develop an individualized treatment plan. Group therapy is the primary treatment modality, supplemented by individual and family therapy, a unique Adult Basic Education component, work therapy, and active involvement in the 12-step programs. Group therapy is important because these clients often reject suggestions from professionals but are willing to accept feedback from peers. Even minor successful accomplishments in the educational program enhance clients' selfesteem and reinforce other areas of growth and change, while work therapy provides an opportunity to learn how to relate to a supervisor and "straight" co-workers.

A case study is presented to illustrate the course of treatment for a typical client. [Article copies available for a fee from The Haworth Document Delivery Service. 1-800-3429678. E-mail address: getinfo@ haworth.com]

Harvey Weiner, Arlin Silberman, Peter Glowacki, and W. Charles Folks are affiliated with Eagleville Hospital, 100 Eagleville Road, Eagleville, PA 19403-1800.

Alcoholism Treatment Quarterly, Vol. 15(4) 1997

1997 by The Haworth Press, Inc. All rights reserved. 
Substance abuse has been called the nation's number one health problem (Robert Wood Johnson Foundation, 1993), and the impact of drugs on America has been summarized by Joseph Califano (1995) as follows:

For 30 years, America has tried to curb crime with more judges, tougher punishments and bigger prisons. We have tried to rein in health costs by manipulating payments to doctors and hospitals. We've fought poverty with welfare systems that offer little incentive to work. All the while, we have undermined these efforts with our personal and national denial about the sinister dimension drug abuse and addiction has added to our society.

Providing effective treatment to addicted criminal justice clients presents special challenges because of the complexity and severity of the biopsychosocial problems which frequently accompany their addiction. The purpose of this paper is to describe the Eagleville Recovery Program, a residential program which has been very effective in treating these clients of particular interest is the program's structure, its multidisciplinary treatment team, and its unique adult basic education and work therapy components.

To provide a framework for understanding the program's treatment philosophy, the paper will begin with an overview of the current understanding of addictive disease. This will be followed by a detailed description of the program, and a case study.

\section{THE CURRENT UNDERSTANDING OF ADDICTIVE DISEASE}

The American Society of Addiction Medicine (Morse and Flavin, 1992) defined alcoholism as follows:

Alcoholism is a primary, chronic disease with genetic, psychosocial, and environmental factors influencing its development and manifestations. The disease is often progressive and fatal. It is characterized by continuous or periodic: impaired control over drinking, preoccupation with the drug alcohol, use of alcohol despite adverse consequences, and distortions in thinking, most notably denial.

In general, the same definition can be used for addiction to drugs other than alcohol. The Greek historian Plutarch said, "Drunkards beget drunkards" (Burton, 1906), and it has long been recognized that addiction, like other chronic diseases, runs in families. Chronic diseases are, by definition, incurable. Examples of chronic diseases include diabetes, high blood pressure, heart disease, asthma, schizophrenia, and bipolar manic-depressive disorder. 
Characteristics common to all chronic diseases include the following:

1. Treatment is effective, but there is no cure.

2. These diseases are progressive and often fatal.

3. There is a lifelong risk for relapse. Rarely does a single episode of treatment result in lifelong remission. To avoid a relapse, the individual must assume personal responsibility for the ongoing management of the disease.

Addicted individuals need to be educated about their disease, and the fact that they will have it for life. Also, they need to understand that abstinence from all psychoactive substances is the only way to guarantee continued sobriety.

To understand the dynamics of addiction, it is important to recognize the difference between abstinence and sobriety. The failure of the current policy of incarcerating addicted offenders without treatment relates to a misconception which equates abstinence and sobriety. The disease of addiction is the continuing desire to use, and it has long been recognized that specific "people, places and things" can cause an intense craving to return, even after years of abstinence (Weiner et al., 1990). Abstinence is simply an absence of, a void, while sobriety means that something has been found to fill the void. Offenders who are incarcerated may be abstinent much of the time (only the myopic clue to the belief that prisons are totally drug and alcohol free; Knopf, 1993), but even prisoners who are abstinent for years may find themselves suddenly overwhelmed with craving if they are not prepared to cope with the temptations and environmental cues they will face upon release. Unless addicted offenders receive treatment during their incarceration, or immediately thereafter, "picking up" (resuming use) is very common. Since the use of drugs or alcohol stimulates the desire to use more in vulnerable individuals, metaphorically awakening sleeping demons, relapse can proceed very rapidly. Furthermore, the readdiction process is telescoped, and it happens much more quickly than the onset of the original addiction.

While sobriety includes abstinence, it is much broader in scope. As noted by veteran therapist Edward Foley (1993),

Abstinence as a goal is a negative. It focuses on suppression, repression and restraint, effort is directed to not doing certain things. People expend much energy in avoiding substances rather than looking to areas or issues needing change or growth. This behavior is known in self-help groups as "white knuckle" sobriety. Given the insidious nature of addiction there is a greater danger of relapse when the focus is so narrow.

Sobriety is an open, wide avenue. While a primary ingredient of sobriety is abstinence, the goal is change and growth: to make progress in living a healthy life free of the dominance of substances. In sobriety, people aim to improve the quality of life. 
Treatment for addicted offenders is an educational and habilitation/rehabilitation process: clients learn about themselves and they learn about addiction as a chronic disease. They also learn that recovering from a chronic disease is a journey, not a destination, and that they must be willing to assume responsibility for lifestyle changes to maintain sobriety.

\section{William James (1986) wrote:}

The greatest revolution in our generation is the discovery that human beings, by changing the inner attitudes of their minds, can change the outer aspect of their lives.

\section{Treatment Population}

Addicted criminal justice clients often have significant medical, psychological and social problems associated with their addiction (see Table1), and effective treatment must address these problems simultaneously, not sequentially (Wallen \& Weiner, 1988, 1989).

Typically, addicted criminal justice clients are from urban areas and almost all are socioeconomically disadvantaged. Most evidenced behavioral problems in school, became involved with the juvenile justice system during adolescence, and experienced early use of mood-altering substances. Many were placed in foster care facilities and dropped out of school before attaining a high school diploma. They have little or no job experience, and few marketable job skills. Their relationships with women tend to be markedly impaired and many have several children but no involvement in parenting. Their children are growing up fatherless, repeating the pattern of their own lives.

Clients often come from a family where parents or siblings are abusing drugs or alcohol. Physical and/or sexual abuse, and abandonment, are also prevalent. Lacking positive role models at home, they identified with antisocial peers in the community. Nurturance during adolescence was often supplied by an organized gang and the individual would participate in the group's activities (including alcohol and drug use) to gain acceptance. Given this background, most clients struggle in treatment to develop self-control, accept limits, and learn to trust others. For many the process is not one of rehabilitation but rather of habilitation, in that they need to learn coping skills and social behaviors which were never developed because of their addiction. 
TABLE 1. Problems Frequently Associated with Addiction in Criminal Justice Clients

\section{MEDICAL}

HIV+

TB

Sexually Transmitted Diseases

Hepatitis

\section{PSYCHOLOGICAL}

Depression

Impulsivity

History of Violence

Antisocial Personality Traits

History of Childhood Neglect and/or Abuse

Pervasive Sense of Despair

Helplessness, and

Hopelessness

Present vs. Future Orientation (immediate gratification vs. sacrifice for long term goals)

\section{SOCIAL}

Unstable Relationships

Unstable Living Arrangements

Alienated From Family

Poverty

Incomplete Education

Few Marketable Job Skills

Teenage Parenthood

Multigenerational Addiction

Friends Who Drink/Use Drugs

\section{THE EAGLEVILLE RECOVERY PROGRAM}

The Recovery Program, which is part of Eagleville Hospital, is a 90-day, 30-bed forensic program for males age 18 and older. Approximately one-hundred and fifty clients are admitted each year, with $60 \%$ successfully completing treatment. This is a significant completion rate given the fact that many of the clients initially seek treatment to avoid incarceration.

The program's staffing pattern is as follows:

- $\quad$ Director (Master's level Social Worker)

- Assistant Director (Master's level Social Worker)

- Psychiatrist (part-time)

- Teacher/Vocational Counselor (Bachelor's level)

- Vocational Psychologist (Master's level)

- Social Worker (Bachelor's level)

- Three Therapists (2 Master's level, I Certified Addictions Counselor) 
Referrals to the program are made by attorneys, public defenders, prison counselors, parole and probation officers, and other treatment programs. There are no involuntary commitments, although clients may be given the choice of entering the program or being incarcerated. The types of legal involvement range from driving under the influence (repeat offenders) through parolees who have been in state prison for a number of years.

Generally, the client's criminal activity has been directly related to the addiction. Individuals with a history of violent crimes against persons usually are not accepted for admission, unless the violent act occurred as a result of intoxication. Most of the clients have abused a variety of mood-altering substances, with alcohol, cocaine, heroin and marijuana being the most prevalent.

The average age of clients is currently 30 years, and 60\% are African-American, 35\% Caucasian, and 5\% Hispanic. In addition to their addiction diagnosis, four out of five clients are typically diagnosed as having a personality disorder, with the majority being. Antisocial Personality Disorder. Major affective disorders are seen in approximately 5\% of the clients. Other diagnostic categories include: Conduct Disorder, Intermittent Explosive Disorder, and Anxiety Disorder.

Although only $5 \%$ of the treatment population are given a formal affective diagnosis, many clients suffer minor depression which is short-lived. Symptoms include feeling "blue," guilt over past deeds, and sleep disturbances. Most clients are initially anxious over being in, a treatment setting and fearful of what will be required of them. Distrust of authority is also a prominent feature, as evidenced by prevarication and passively resisting instructions. Intimidation of peers often occurs early in treatment, and this behavior is especially prevalent in clients just released from incarceration. In prison this served as a protective defense as well as a survival technique. In the Recovery Program intimidation can range from obtaining cigarettes from a weaker peer to verbal threats, which might include a statement such as, "If we were out on the street, I would..." Throughout the history of the program, actual physical confrontation has been rare. A cardinal rule of the program is that violence or a serious threat of violence results in immediate discharge.

\section{Assessment and Treatment Planning}

Within the first 72 hours following admission, the social worker conducts a Psychosocial Evaluation, the psychiatrist completes a Psychiatric Evaluation, the teacher completes an Educational Assessment and the vocational counselor completes a Vocational Assessment. A physical examination is performed, appropriate laboratory tests are ordered, psychological testing is provided when needed, and a Family Assessment is scheduled if indicated. Once the assessments are completed, the assistant director prepares a Diagnostic Summary of Assessments, which summarizes and integrates the significant findings in each of the assessments.

The team reviews the Diagnostic Summary of Assessments by the client's fifth day in the program and formulates an individualized treatment plan which notes specific, time-referenced, measurable objectives. The plan also notes the services planned for each client, and the staff member who will have primary responsibility for helping the client achieve each objective. The 
plan is then reviewed with the client, and modified if necessary. Each client is given a copy of his treatment plan for reference purposes.

Clients who are experiencing difficulty following program rules or their treatment plan may have a behavioral agreement or written contract, developed. Repeated failure to follow the treatment plan or behavioral agreement can result in the client being discharged from the program.

\section{Program Schedule}

The major components of the program include: (1) a daily 6-hour clinical program;

(2) a work therapy experience of 12 hours per week; and (3) adult basic education, vocational counseling, and active involvement in 12-step meetings.

$\begin{array}{ll}\text { 8:00 - 9:00 a.m. } & \text { Orientation and "Back to Basics" Meeting } \\ \text { 9:00 - 9:45 } & \text { Program Meeting } \\ \text { 10:00 - 12:15 p.m. } & \text { Group Therapy } \\ \text { 12:30 - 1:00 } & \text { Lunch } \\ \text { 1:15- 2:00 } & \text { Educational Seminar or Individual Sessions } \\ \text { 2:00 - 3:00 } & \text { Adult Basic Education } \\ \text { 3:00 - 4:45 } & \text { Work Therapy } \\ \text { 5:00 - 5:45 } & \text { Dinner } \\ \text { 6:00 - 7:00 } & \text { Gym Activities } \\ \text { 7:00 - 8:15 } & \text { Work Therapy or Free Time } \\ \text { 8:30 -10:30 } & \text { I 2-Step Meeting (on or off campus) or } \\ & \text { House Meeting, with Residential Staff }\end{array}$

The day begins with a "Back-to-Basics" meeting to provide an orientation for new clients by drawing on the experiences of senior clients. Program rules and behavioral norms are reinforced, and clients are taught techniques for communicating in an assertive and non-threatening manner. Following "Back-to-Basics," a 45-minute program meeting occurs with clients encouraged to hold one another accountable for problematic behaviors and attitudes. 


\section{Group Therapy}

After the program meeting, clients attend group therapy for two hours. Group size is limited to ten clients, each of whom has treatment objectives identified for work in the group. Group therapy provides a common bond for individuals who have lost a significant component of their identity by enforced abstinence, in that a cohesive group provides the beginning of a new identity as a recovering person. Group therapy is also important because these clients often reject suggestions from professionals but are willing to accept feedback from peers. Through listening to peers, clients discover that they are not alone in being powerless to control their addiction, and they gain hope that recovery is possible.

Similar to the way in which beginning drug users learn the skills required to maintain an addiction from their peers, and first-time inmates learn how to survive in prison, senior group members help new clients assimilate into the therapy group. Many of these clients have experienced repeated relapse, and the group becomes a learning laboratory where prior failures can be examined to prevent someone else from making the same mistake. The ability to give and receive support in the group also prepares the individual to utilize 12-step programs to maintain recovery in the community.

The primary focus of group therapy is the "here and now," with clients encouraged to examine their relationships with peers. These relationships provide information about how clients manage their relationships with the significant individuals in their lives. With guidance from the therapist, the group is a powerful force in helping each client recognize the distortions in his personal belief system and the impact of his behavior on others. Each client receives feedback about his selfdefeating behavior patterns, and is taught techniques for modifying these behaviors. Role-playing is frequently utilized to allow the client to view a "mirror image" of his behavior, or to practice a new technique such as verbal assertiveness. By participating in the group process and completing behavioral objectives, the client develops the ability to work toward long-term goals rather than behaving impulsively and seeking immediate gratification. Group therapy is the primary modality, with individual and family sessions scheduled as needed.

After lunch, there is a one-hour educational seminar. Each day is utilized by a different staff member: the vocational counselor teaches job search skills and discusses issues related to employment, the teacher provides information about activities for daily living (i.e., budgeting, shopping, using public transportation, and personal hygiene) and an Addiction Education Workshop, and the social worker conducts a Relapse Prevention Workshop.

\section{Adult Basic Education}

Three afternoons per week all clients attend an Adult Basic Education program. Many of the clients lack basic academic skills and have not attained a high school diploma because early involvement with drugs and/or alcohol resulted in a premature end of formal education. Limited academic skills contribute to low self-esteem and make it difficult to obtain a good job, which perpetuates feelings of helplessness and hopelessness. Because a positive self-image and feelings 
of self-worth are so important for recovery and continued sobriety, basic academic skills and a high school diploma are particularly relevant for these clients.

The educational program focuses on improving basic academic skills, General Equivalency Diploma (GED) preparation, and skills retraining. New students are given a screening test and each student is provided with an individualized curriculum for learning. He is then given appropriate materials and matched with a teacher or volunteer tutor.

Students with a high school diploma are encouraged to upgrade their academic skills. Typewriters, computers with word processing capability, and a printer with the capacity for design and newsletter production allow for the development of new and valuable skills. The educational program is particularly important with this population because even minor successful accomplishments enhance self-esteem and reinforce other areas of growth and change.

\section{Work Therapy}

All clients participate in a 12-hour per week work therapy experience, for which they are paid minimum wage. The job assignments are usually in the Hospital's housekeeping and food service areas, in the types of jobs that are available to them when they return to the community. For many clients this is their first legal, socially acceptable work experience, and it presents an opportunity to learn how to relate to a supervisor and "straight" co-workers. It also provides a job history to present to potential employers. Clients pay a small portion of their room and meal costs, which allows them to feel that they are investing in their recovery rather than remaining passively dependent on institutions. Also, they are able to save a small amount of money to assist in the transition to independent living upon completion of treatment.

Evenings and weekends are utilized to introduce and reinforce concepts from the 12-step programs, with guest speakers providing an opportunity for clients to hear that it is possible to change their lifestyle, remain drug and alcohol free, and feel good about themselves. Step one is of primary importance in that clients need to understand how accepting their powerlessness over alcohol and drugs empowers them to move forward in all other areas of life.

Recreational activities are also provided during evenings and weekends. Correctional facilities generally provide "macho" activities, such as weightlifting, boxing, and competitive sports. By contrast, staff in the Recovery Program attempt to design activities which focus on use of leisure time to have fun, relax and enjoy the company of others.

\section{Aftercare Planning and Follow-Up}

As treatment progresses, the client begins to develop an Aftercare Plan with the assistance of the social worker. Participation in the Relapse Prevention Workshop helps him understand relapse as a process that often begins with subtle emotional, attitudinal, and behavioral changes. The acronym HALT is useful in this respect (Hungry, Angry, Lonely, Tired), identifying times when it might be most tempting to reach for a drink or drug. The client identifies his own potential relapse "triggers " and completes a Relapse Prevention Workbook. Family involvement 
is encouraged, if appropriate, and the client learns about resources in the community to prevent relapse and assist in the transition to independent living. The social worker assists the client in establishing contact with aftercare resources, and then attempts to follow up by contacting the aftercare facility one week after discharge to determine the outcome of the referral. The social worker also encourages clients to contact the Recovery Program by telephone if they experience difficulty implementing the Aftercare Plan and need further assistance. At six and twelve months after discharge the social worker mails a questionnaire to the former client inquiring about his status and offering assistance if needed. Unfortunately, accurate follow-up data is not available because many clients fail to return their questionnaires. Clients who are doing well are much more likely to return the questionnaires, because those who are not doing well often feel embarrassed or ashamed.

The following section presents a case study to illustrate the course of treatment for a typical client.

\section{CASE STUDY}

Mr. Doe is a 30 year old single Caucasian male who had been incarcerated for the past six months for a parole violation of not reporting. Prior to incarceration he was living with his mother and drinking two gallons a day of a mixture of gin, whiskey and wine. He also smoked cocaine and marijuana daily. As a result of his addiction he had problems with his mother, and with his children's mother. He last worked three years ago for a janitorial service but lost the job because of his addiction. He has five convictions for robbery, burglary and physical abuse of his children's mother, with a total of five years of incarceration. He has had withdrawal symptoms, including delirium tremens, auditory and visual hallucinations and flashbacks. He denied seizures but reported blackouts, paranoid ideation and nightmares. He denied any overdoses or suicide attempts but admitted he had been assaultive when high.

\section{Substance Abuse History}

At age 9, he first drank whiskey at a friend's home, and he gradually increased his drinking up to the present time. He also tried cough syrup for one year. He started cocaine at age 26, and used a combination of speed and heroin for several years. He had been detoxed seven times. He attended 12-step meetings intermittently and stated that his longest period of sobriety was a few weeks.

\section{Medical History}

The client has one bullet in his body. He had a cerebral concussion from a fall when he was very young, which resulted in his being hospitalized for two months. He felt he was always slow in school as a result of this injury. Recent HIV and tuberculin tests in prison were negative.

\section{Family History}


Mother is 50, not involved with drugs or alcohol. His father died in 1984 from drinking. His parents separated when he was three or four years old because his mother was involved with another man. Mr. Doe is the third of seven children; he has four brothers and two sisters. Two brothers and one sister are addicts. There is no psychiatric history or any suicidal or homicidal behavior in the family background.

\section{Developmental and Social History}

Mr. Doe was born and raised in Philadelphia and states he had an unhappy childhood and adolescence because he lived in a crime-ridden, drug-infested neighborhood. He has scars from years of gang fighting, reported many beatings by his mother, and stated he was blamed for anything that happened in the neighborhood. His stepfather, who treated him well, died when Mr. Doe was 16 years of age. He quit school at age 14 because he was not learning anything, and continued in gang warfare and other antisocial activities. He did odd jobs, such as cleaning, shining shoes, washing cars and shoveling snow.

At age 11 he was charged with a stabbing and spent one month in a youth correctional facility, then placed on probation. At age 14, he was convicted of a burglary and spent four months in another correctional facility. He ran away and was apprehended and returned to the correctional facility. He came out when he was approaching his 18th birthday and at age 19 he was apprehended for robbery and sent to prison for two years. When he was 18, he met a girl with whom he had a significant relationship for ten years, with the birth of two daughters (currently 9 and 12 years of age). He maintains contact with his children, and feels an obligation to support them. He had numerous other sexual relationships but knows of no other children.

\section{Religion}

Protestant. Client occasionally goes to church.

\section{Course of Treatment}

Mr. Doe participated in the assessment process but tended to minimize the severity of his problems and blame others for his life circumstances. The Diagnostic Summary of Assessments indicated that Mr. Doe: (1) was in relatively good health. (2) had a limited understanding of addiction as a disease; (3) tended to remain dependent on women and institutions; (4) was seeking treatment primarily as a way of getting out of jail; and (5) had no real sober support system in the community.

The treatment team reviewed the Diagnostic Summary of Assessments and met with Mr. Doe to develop his treatment plan. Two main problems were identified, related to Mr. Doe's addiction and his dependence on women and institutions. Long- and short-term goals were developed for each problem, with the short term goals having time-referenced, measurable objectives. Also, specific staff members were given primary responsibility for helping Mr. Doe

achieve each objective. Mr. Doe's progress in achieving specific treatment objectives in relation 
to each problem is summarized below. (For descriptive proposes, a separate analysis is presented for each problem. In actuality, he was working on both problems simultaneously.)

Problem 1: Severity of Addiction and Multiple Relapses.

Long-Term Goal: Maintain Sobriety in the Community.

Short-Term Goal: Accept Responsibility for Recovery.

Objectives for first month:

1. Develop a list of 10 negative consequences of your addiction and share them in group by the end of the second week. (Staff member: therapist.)

2. Attend 12--step meetings on campus three times per week and report in group each week about your experiences in these meetings. (Staff member: therapist.)

3. Attend the Relapse Prevention seminar and identify three of your relapse "triggers " by the end of the third week. (Staff member: social worker.)

4. Meet with the social worker at least once to identify resources needed to stay sober in the community. (Staff member: social worker.)

Mr. Doe was able to complete objectives 1 and 2 in the first month, but objectives 3 and 4 were continued into the next month. Also, the treatment team added the following objectives for the second month:

5. Attend one off-campus 12-step meeting per week and talk in group about your experiences there. (Staff member: therapist.)

6. Contact your parole officer and ask if there are specific requirements for housing and treatment after discharge. (Staff member: social worker.)

During the second month, Mr. Doe attended off-campus meetings and stated that he could relate to the people he met there. In group, he identified returning to his mother's house, hanging around with old friends who get high, and being bored because he was not working as relapse "triggers. " Mr. Doe also contacted his parole officer and reported getting angry because the parole officer suggested going to a halfway house.

For the third month, the team added the following objectives:

7. Visit one or two halfway houses to identify options for aftercare. (Staff member: social worker.)

8. Attend at least one 12-step meeting in the community where you plan to live and ask for a temporary sponsor. (Staff member: social worker.)

During the third month, Mr. Doe identified the buildup of anger and resentment, as well as trying to make fast money, as additional relapse "triggers." He arranged to be interviewed at a halfway house and was accepted for admission. He also attended several community 12-step meetings and found a temporary sponsor. 
Problem 2: Dependence on Women and Institutions.

Long-Term Goal: Develop Independence.

Short-Term Goal: Be Assertive and Improve Interpersonal Skills.

Objectives for the first month:

1. Develop a list of five benefits and five negative consequences of living in institutions, and discuss them in group by the end of the second week. (Staff member: therapist.)

2. By the end of the second week, talk with your therapist about your relationship with your mother and other women in your life and try to identify patterns in these relationships. (Individual sessions with therapist.)

3. By the end of the third week, read the Assertiveness booklet and discuss in group whether you see yourself as primarily passive, assertive or aggressive. (Staff member: therapist)

4. Attend the Adult Basic Education school program three times per week to work toward attaining a General Equivalency Diploma. (Staff member: teacher.)

5. Improve your work habits by participating in work therapy in the Hospital's Housekeeping Department, beginning the first week. (Staff member: vocational counselor.)

During the first month, Mr. Doe completed objectives 1 and 5, and he was making good progress on objective 4 . He attended individual sessions with his therapist as noted in objective 2, but was struggling to identify patterns in his relationships with women. Regarding objective 3, Mr. Doe identified himself as assertive, but his peers observed that he argued with them whenever they criticized him.

For the second month, the team added the following objectives:

6. Role play examples of assertive behavior in group at least once per week.

7. To practice listening, give no response when getting input from peers in group. (Staff member: therapist.)

During the second month, Mr. Doe was able to identify a pattern of dependence on women and feeling inadequate about doing things like paying rent and shopping for clothes. Also, he stopped arguing when receiving input from peers in group.

For the third month, the team added the following objectives:

8. Schedule a family session with your mother and the mother of your children to discuss going to a halfway house and ways to support your independence. (Staff member: therapist.)

9. Assist in role-plays in group to demonstrate passive, aggressive and assertive behavior for new group members. (Staff member therapist.)

During the third month, Mr. Doe participated in a family session and he was able to identify ways to remain involved with his children. His family encouraged him to complete the halfway 
house stay. He actively participated in role-plays in group, but in real interactions with peers he needed occasional reminders about behaving aggressively.

\section{Discharge and Aftercare Plan}

The client was discharged after three months, successfully completing the program with progress realized on his major treatment goals. Aftercare plans included relocation to a halfway house and continuing therapy at an outpatient clinic (his first appointment was scheduled). He listed the 12-step meetings he would be attending, and indicated that he would report to his parole officer as directed. He also made plans to seek employment.

\section{Follow-Up}

At one week, six month and 12 month follow-up, it was found that Mr. Doe had been able to maintain sobriety. He was holding an entry level job in the service industry, had no new arrests, maintained contact with his children, and reported regularly to his parole officer.

\section{SUMMARY}

Many of the nation's major social, economic and healthcare problems are directly related to alcohol and drugs, and addicted criminal justice clients present particular challenges because of the complex problems which frequently accompany their addiction. The Eagleville Recovery Program has achieved notable success using a multidisciplinary team and a structured program which includes group and work therapy, educational activities, and a variety of other therapeutic interventions. It is hoped that the overview of addictive disease, detailed program description and illustrative case study will be of help to other clinicians who are working with these clients. 


\section{REFERENCES}

Burton, Robert. (1628). Plutarch quoted in 77ie Anatomy of Melancholy, New York. Vintage 1977, p. 213.

Califano, Joseph. (Jan. 29, 1995). "It's Drugs, Stupid." New York Times Magazine, p. 40.

Foley, Edward. (Jun 8, 1993). Private correspondence.

Fuller, Thomas. (1732). Gnomologia.

James, William. (1986). In Be All 7hat You Are by James Fadiman. Westlake Press, Seattle, p. 1.

Knopf, Alison, Ed. (Dec. 15, 1993). "Judge Outraged by Accessibility of Drugs in Federal Prisons." Substance Abuse Report, Washington, DC, Vol. 29, No. 24, P. 5.

Morse, Robert and Daniel Flavin (Aug. 26, 1992). "The Definition of Alcoholism." Journal of the American Medical Association, Vol. 2 68, No. 8, p. 1013.

Robert Wood Johnson Foundation. (Oct. 1993). Substance Abuse.- The Nation's Number One Health Problem. Princeton, NJ.

Wallen, Mark and Harvey Weiner. (1988). "The Dually Diagnosed Patient in an Inpatient Chemical Dependency Treatment Program." Alcoholism Treatment Quarterly Vol. 5, No. 112, pp. 197-218.

Wallen, Mark and Harvey Weiner. (Apr-Jun, 1989). "Impediments to Effective Treatment of the Dually Diagnosed Patient." Journal of Psychoactive Drugs, Vol. 2 1, No. 2, pp. 161-168.

Weiner, Harvey, Mark Wallen and Gloria Zankowski. (Apr-Jun, 1990). "Culture and Social Class as Intervening Variables in Relapse Prevention with Chemically Dependent Women." Journal of Psychoactive Drugs, Vol. 22, No. pp. 239-248. 